\title{
Development of An Automated Airport Pavement Image Collection System
}

Chau Lee

Professor, Department of Civil Engineering, National Central University Chungli, Taiwan , R.O.C.

C.F. Chen

Associate Professor, Department of Civil Engineering, National Central University Chungli, Taiwan, R.O.C.

Shu-Meng Huang

Graduate Student, Department of Civil Engineering, National Central University Chungli, Taiwan, R.O.C.

Chun-Jung Hsu

Graduate Student, Department of Civil Engineering, National Central University Chungli, Taiwan, R.O.C.

Shu-Wang Sheu

Assistant Professor, Department of Civil Engineering, Ching-Yun Institute of Technology, Taiwan, R.O.C.

Follow this and additional works at: https://jmstt.ntou.edu.tw/journal

Part of the Civil and Environmental Engineering Commons

\section{Recommended Citation}

Lee, Chau; Chen, C.F.; Huang, Shu-Meng; Hsu, Chun-Jung; and Sheu, Shu-Wang (2002) "Development of An Automated Airport Pavement Image Collection System," Journal of Marine Science and Technology. Vol. 10: Iss. 1, Article 1.

DOI: $10.51400 / 2709-6998.2294$

Available at: https://jmstt.ntou.edu.tw/journal/vol10/iss1/1

This Research Article is brought to you for free and open access by Journal of Marine Science and Technology. It has been accepted for inclusion in Journal of Marine Science and Technology by an authorized editor of Journal of Marine Science and Technology. 


\title{
DEVELOPMENT OF AN AUTOMATED AIRPORT PAVEMENT IMAGE COLLECTION SYSTEM
}

\author{
Chau Lee*, C.F. Chen**, Shu-Meng Huang***, \\ Chun-Jung $\mathrm{Hsu}^{* * *}$, and Shu-Wang Sheu****
}

Key words: Airport pavement, GIS, GPS.

\section{ABSTRACT}

Airport pavement maintenance is an extremely important link in any airport pavement management system. How to quickly and effectively perform pavement surveys and data collection at today's very busy airports, while minimizing disruption to the airport's normal operation, is a major issue in airport pavement maintenance management research.

This study uses a van to perform photographic surveys, and employs a global positioning system (GPS), geographic information system (GIS), image caption device, and the audio acquisition method to develop an automated airport pavement image collection system. This system currently is able to display a pavement image, slab name, and damage location coordinates on the same screen, and can automatically acquire a picture of the damaged slab. Because the system can greatly speed up pavement surveys, and the image can be stored into each slab's database of pavement management system, it should be extremely useful in airport pavement maintenance work.

\section{INTRODUCTION}

Pavement surveys can be considered as the most essential process for the pavement administration and maintenance. A detailed and accurate survey can help authorities grasp types of damage occurred and degree of its severity. Authorities can also construct appropriate strategies of pavement maintenance accordingly and effectively to promote the capabilities of pavement administration. Besides, it can aid to prolong the service life of pavement and high qualities of safety flight.

A typical survey is proceeded by a group of inspectors with simple equipment. Such kind of method is not

Paper Received June 6, 2001. Author for Correspondence: Chau Lee.

*Professor, Department of Civil Engineering, National Central University Chungli, Taiwan, R.O.C.

**Associate Professor, Department of Civil Engineering, National Central University Chungli, Taiwan, R.O.C.

***Graduate Student, Department of Civil Engineering, National Central University Chungli, Taiwan, R.O.C.

****Assistant Professor, Department of Civil Engineering, Ching-Yun Institute of Technology, Taiwan, R.O.C. only labor-intensive but also time- consuming and is ineffective to rush pavements of airports. Recently, automation survey has therefore become a key point to develop pavement survey [1]. Schwarz and El-Sheimy applied system of vehicle- carried cameras, laser sensors and other sensor systems to inspect objects from close ranges of pavement [2]. Bursansesu and Blais applied vehicle- carried laser sensor systems to collect and analyze data of pavement damage [3]. Ali, Gennert, and Clarkson developed a vehicle-carried camera that travels along the road taking pictures of pavement, which are analyzed to evaluate the type, severity, and distribution of surface cracks and patches [4]. Currently, Wang used a van filled with high-tech computer and video equipment to digitally record highway surfaces, the multimedia highway information system (MMHIS). This makes critical information about the roads readily available to engineers [5]. Although these systems measured the location of pavement damage by GPS function, their image data was not yet integrable with a GPS receiver, which caused the difficulties of data arrangement and judgement.

There are more then ten kinds of commercialize automation inspection vehicles [6-11], which inspect ordinary roads of surface damage, ruts and roughness by means of the photographing and video together with related sensor equipment. However, they are not only expensive but are ineffective especially if the sub-units of damage image and their locations are in an independent status with deficiency of dispersed data [12]. There are different distribution features between airport and road pavement. The latter is with reticulated structures, which can identify a location of damage by marking its mileage; while the former is with self-structures, which are roughly distinguished as runways, taxiways and parking apron. Because there are no obvious signs or artificial features on the pavement, it is hard to figure out the specific location of damage. It then becomes a very important issue to construct effective, accurate pavement surveys as well as to specify and record the location of pavement damage accurately for the re- 
search of pavement maintenance and administration. To approach this theory, we have effectively and economically developed a research by using a foolproof pavement inspection system, transported by a common vehicle, and took the Sung San airport as example, to integrate GPS, GIS and pavement image into one synchronize image display. The execution of synchronously integrating pavement image, codes of slab names and locations of damage shall advance a great step for the capabilities of data analysis and identification in automation pavement inspection technology.

\section{AN AUTOMATED AIRPORT PAVEMENT IMAGE COLLECTION SYSTEM}

\section{System Goals}

Taking real airport operating conditions into account, this study incorporated the coordinates positioning function of GPS and the spatial and attribute data searching function of GIS into the development of a full-function, regular, large-scale pavement survey method employing a vehicle-mounted image collection system. The GPS allows the coordinates of each pavement slab to be determined, while GIS can simultaneously record spatial and attribute data. Besides increasing survey speed and making subsequent interpretation more efficient, this method can use automatic image acquisition technology to automatically select and acquire images of damaged pavement, saving the expense of searching manually for pavement damage. The incorporation of GPS and GIS functions in an airport pavement survey system thus should be extremely useful to airport pavement management. We hope that this survey system can effectively and accurately detect pavement damage and ascertain its correct location. Besides the time and manpower expense of survey work, the system seeks to make pavement surveys safer.

\section{System Components}

The system is composed of the four major components of GPS, GIS, an image collection system (V8/ D8 camera), and an image caption mixer (DECADE). The structure of this system is shown in Fig. 1. The following is a summary of the functions of each component:

(1) GPS/GIS position-finding system: The GPS system transmits position data to the computer end via an RS-232C port. The GIS system is responsible for finding GPS coordinates and the corresponding slab name, and transmits slab names and coordinates in the form of code numbers to the image caption device via an RS-232C port. The slab names and coordinates are then displayed on the proper part of images.

(2) Image collection system: The V8 camera records pavement slab damage for subsequent interpretive use. To improve resolution, a digital camera may also be used.

(3) Image caption mixer: This device has two inputs and one output terminal. The input terminals include one AV image input terminal and one RS$232 \mathrm{C}$ input terminal. The AV image input terminal receives signals from the V8 camera. The RS-232C terminal receives encoded signals from the computer. This device automatically mixes the two captions with images, and sends output via an AV terminal to a video player/recorder for recording or displaying. A monitor may ordinarily be used simultaneously with the video player/recorder to check visually whether the recorded data is correct.

(4) Automatic image acquisition: Computer software selects and acquires images of damaged pavement from the recorded videotape, and saves the images as computer files. To facilitate subsequent interpretation and maintenance work, the location, slab number, and image corresponding to each piece of data is recorded.

\section{SYSTEM DEVELOPMENT}

\section{Front-end Processing}

(1) Pavement position finding: A number of reference coordinates of the airport's most important locations are selected. GPS is used to determine the coordinate locations of the airport's runways, taxiways, and parking aprons.

(2) Map preparation: A digital map of the airport is created, and positional relations established with the GIS software are input. As for areas with rigid pavement, each slab is represented in the spatial data as a polygon. In the case of areas with soft pavement, since the surface lacks the obvious joints that are used to distinguish the slabs of rigid

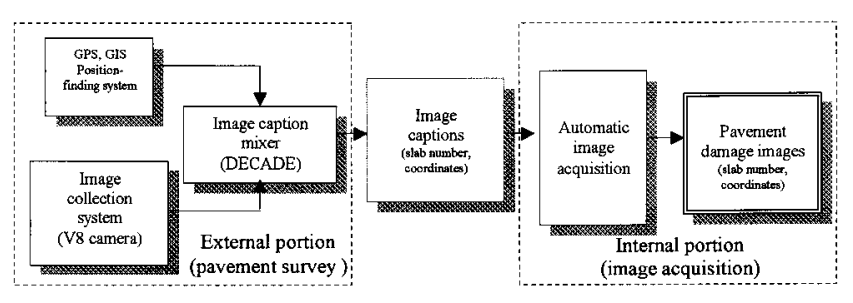

Fig. 1. The structure of the survey system. 
pavement, it is necessary to create virtual slabs of appropriate dimensions on the map. The creation of these virtual slabs will facilitate subsequent storage of slab attribute data in the GIS system.

(3) Naming of slabs: Because of the vast number of slabs, data search efficiency will be adversely affected unless a systematic classification system is adopted. Pavement slabs are therefore first classified as R (Runway), WT (West Taxiway), ET (East Taxiway), and $\mathrm{P}$ (Apron), etc., on the basis of their use and location, and then named using letters and numbers. Slab names are thus in the form of R-A12 and WT-B25, for instance.

\section{System Assembly}

The system's principles and assembly approach are as follows:

\section{(1) Position finding model:}

To prevent the existing GPS system from being affected by the environment, and to reduce the abnormal jumping of coordinates to the absolute minimum, this study adopted Kalman filtering [12].

In addition, because GPS position finding cannot determine the location of a close-up photograph, it is necessary to incorporate other positional information if it is wished to truly determine the slab location. We therefore used the guideline principle of surveying to find the distance to the close-up location. We took the GPS antenna location as a base point, found the azimuth of the carrier path $(\theta)$ from the GPS, and indirectly obtained the horizontal deviation of the distance, which was then used to derive the distance. The distance between the GPS location and the location of the closeup photograph is basically a constant, and can be found using a range finder or a measuring tape.

The distance measured between the central location in the camera screen and the center of the GPS antenna (oblique distance) and the vertical distance between the GPS antenna and the ground can be used to derive the horizontal distance using the Pythagorean theorem, as show in Fig. 2:

To obtain the deviations $\Delta x$ and $\Delta y$, it is necessary to first obtain the azimuth from the position-finding information, and then measure the oblique angle $L$ from the center of the GPS antenna to the center of the camera screen and the vertical distance $H$ from the center of the antenna to the ground. The horizontal distance is then derived as:

$$
S=\sqrt{L^{2}-H^{2}} \text {. }
$$

The deviations $\Delta x$ and $\Delta y$ are obtained as follows:

$$
\Delta x=S \cdot \sin \theta
$$$$
\Delta y=S \cdot \cos \theta
$$

The photograph's central coordinates $X$ and $Y$ are finally found by:

$$
\begin{aligned}
& X=x_{G P S}+\Delta x \\
& Y=y_{G P S}+\Delta y
\end{aligned}
$$

After the location of the center of the photograph is indirectly derived by the about method, the corresponding slab location and name can be found in the GIS database to facilitate storage of the record, as shown in Figs. 3, 4.

\section{(2) Recording Method:}

Two methods are used to insure that the photograph's location corresponds to the correct slab, the image captioning method and the audio acquisition method.

\section{A. Image Captioning Method:}

This method uses an image caption mixer to incorporate the location coordinates and the slab name found in the GIS database into the photographic image signal. The caption line is displayed in a specified location on the screen, and it is recorded simultaneously with the image. Input from both a GPS unit and a V8/D8 camera are required, and the following processing steps are implemented:
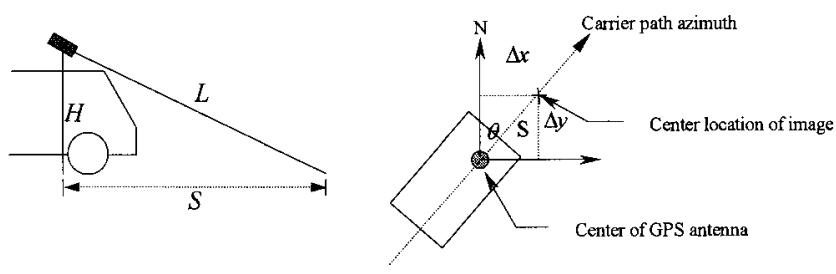

Fig. 2. Position finding Model.

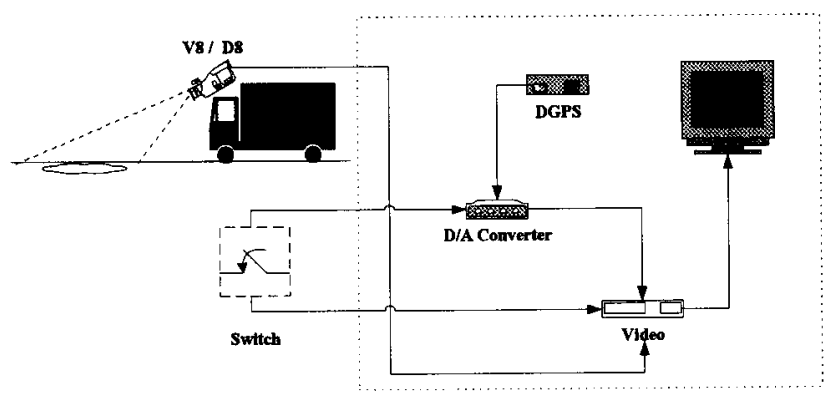

Fig. 3. Schematic diagram of onsite processing. 
a. The GPS position-finding device transmits the current location to the computer in NMEA (National Marine Electronics Association) format via an RS$232 \mathrm{C}$ serial port. The computer will retrieve the corresponding slab number and coordinates from the GIS database when it receives positional information. After converting this information into a format recognized by the image caption device, the computer transmits it to the image caption device for processing via an RS-232C serial port.

b. Another input is transmitted from the V8/D8 camera, which is responsible for recording images showing the condition of the slab. The camera transmits its output signal to the image caption device for processing via an AV terminal.

c. The image caption device integrates the about two types of signal, and displays a caption on a specified part of the screen. Completed image signals are transmitted via an AV terminal to a video recorder for storage.

d. To monitor and control the photographic process, we connected the video recorder's output AV terminal to a monitor.

\section{B. Audio Acquisition Method:}

When work personnel are performing an onsite survey, the coordinates of road damage will be automatically converted to an analog audio signal whenever an operator presses a convenient button. This audio signal is then transmitted to the input terminal of a video player/recorder. The industrial video player/recorder will then switch from the default $3 \mathrm{X}$ recording speed to normal record speed for a period of approximately five seconds. It will then automatically switch back to $3 \mathrm{X}$ recording speed after the five seconds are up. During subsequent processing in laboratory, the recorded videotape will be played back, and the audio signal recorded by the audio decoder will be restored to the original coordinate information. The signal is then transmitted via a serial port to a computer. The computer's image acquisition software will acquire

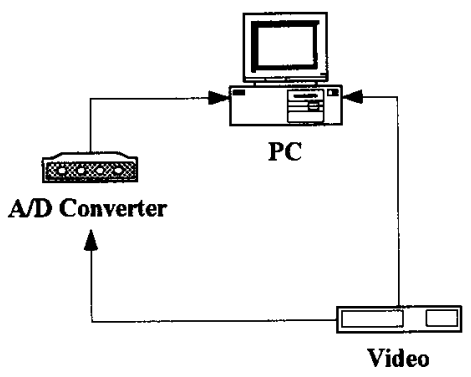

Fig. 4. Schematic diagram of laboratory processing. images on the basis of the coordinate signal, automatically recording the location of the images and creating image files.

Input is required from two major instruments while the system is being operated, the GPS device and V8/D8 camera, entailing the following steps:

a. During outdoors operations, the GPS receiver will receive the on-site location and transmit it via an RS232C port in NMEA 0183 format to a D/A converter, which converts the digital signal into audio signal output.

b. The V8/D8 camera is responsible for recording images of the pavement. Output from the camera is transmitted via an AV terminal to a video player/ recorder for recording. The video player/recorder meanwhile can output images via an AV terminal to a monitor, allowing survey personnel to observe damage.

c. When survey personnel find pavement damage, they will press a switch to activate a D/A converter. The D/A converter converts GPS position information into an audio signal output, which is transmitted to a video recorder via an audio AV terminal for recording.

d. When the switch is pressed and the GPS audio signal recorded, the video player/recorder switches from the $3 \mathrm{X}$ recording speed to normal record speed for a period of approximately five seconds, and then automatically switch back to $3 \mathrm{X}$ recording speed. The use of an industrial video recorder seeks to save processing time. It is not necessary to view every bit of pavement when the pavement is normal, and images must be acquired only when there is surfaced damage. Normal pavement surface is thus played back at $3 \mathrm{X}$ speed, saving playback time and improving working efficiency.

e. The recorded videotape is played back during the subsequent processing stage. When the playback reaches an area of surface damage, the GPS position audio signal will be output to an A/D converter for conversion into a digital GPS position signal, which is transmitted to the computer via a serial port. After the computer receives the signal via its serial port, it activates its image acquisition software. The software acquires the image and saves it as an image file, and records the location, slab number, and image file corresponding to that piece of data. This information will facilitate subsequent interpretation and maintenance work.

\section{System Tools}

When mounted on a van, the system can be used to perform a video pavement survey during the nighttime. 
Major pieces of necessary equipment include illumination lamps, a camera, a GPS receiver, a monitor, a video player/recorder, and a notebook computer.

\section{Assembly of Equipments}

The system uses a nine-person van as the vehicle carrying survey equipments. Illumination lamps, camera, and GPS antenna are mounted on the top of the van, as shown in Fig. 5. The monitor, notebook computer, and video player/recorder are located within the van, as shown in Fig. 6.

\section{FIELD TRIAL}

\section{Trial Performance}

Because of frequent aircraft takeoffs and landings during the daytime, pavement survey can be performed only at night. The system was operated by a driver and a monitor observer at the survey speed of approximately $15 \mathrm{~km} / \mathrm{hr}$. The size of images was approximately $3 \mathrm{~m} \times$ $4 \mathrm{~m}$.

\section{Trial Results}

After numerous tests and modifications, the system was used to perform an on-site survey of the runways and taxiways at Sungshan Airport [14]. The video tape recorded during the pavement survey was analyzed by computer, which automatically selected and acquired images of damage pavement, which were saved as image files. In the caption of one of the images shown in Fig. 7, WST-G32 the slab number and 306409.3, 2756453.3 are the coordinates of center of the picture.

\section{Images Subsequent Processing}

We used GIS function storing and displaying spatial and attribute data to create the Airport Pavement Repair System for Sungshan Airport [14]. This system

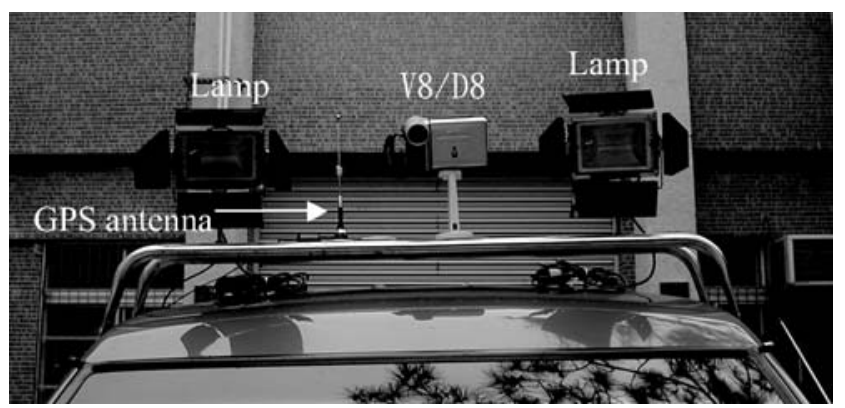

Fig. 5. External photographic equipments mounted on the van roof. provides query function for searching basic information and past repair records of each slab of airport pavement, display the distribution chart of different distress types, display the statistic quantity of the distress types, and display images of distressed slab before and after the repair, as shown in Fig. 8. In the future, the acquired images of distress pavement can directly be stored into each slab's database of pavement management system.

\section{Discussion of Results}

Trials of the system had verified that it is safer and more efficient than conventional manual walking surveys. The successful adoption of GPS and GIS functions allows the pavement image, slab name, and damage location coordinates to be displayed in the same frame. This integration of pavement damage data increases data resolution. The video tape of the pavement can be easily used to acquire images of damaged pave-

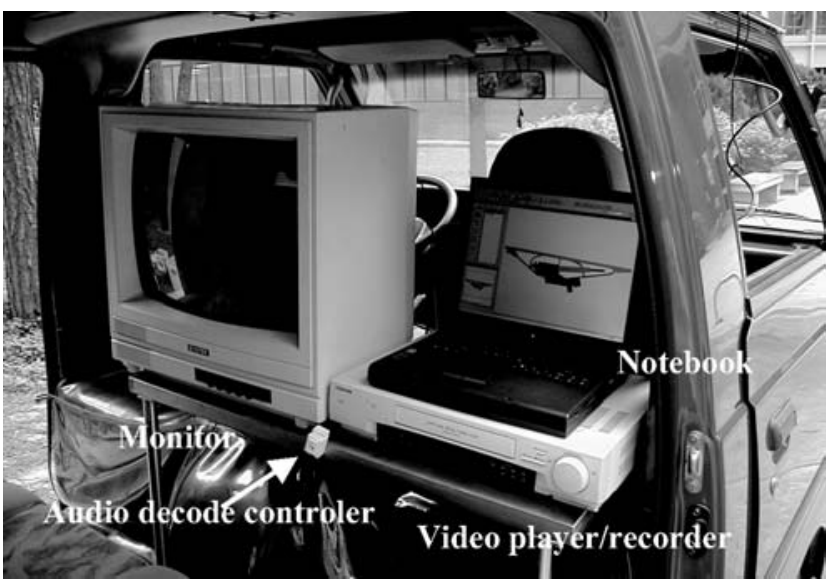

Fig. 6. Image collection and control equipments inside the van.

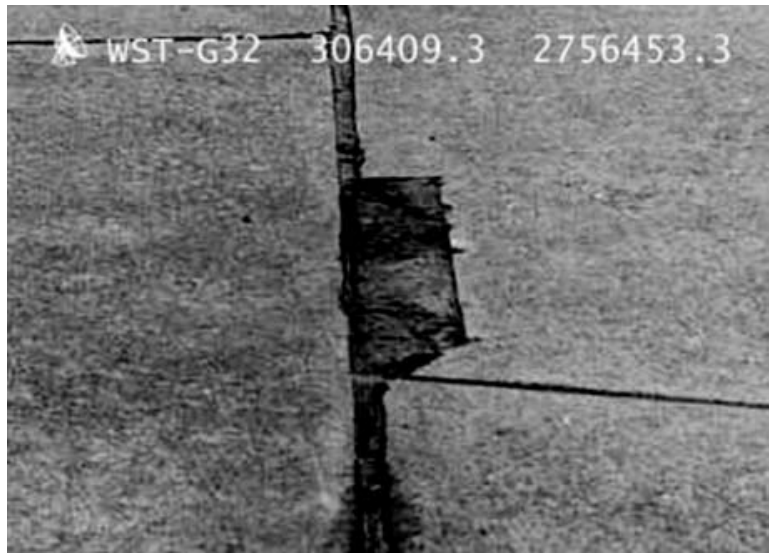

Fig. 7. Automatically acquired pavement images. 


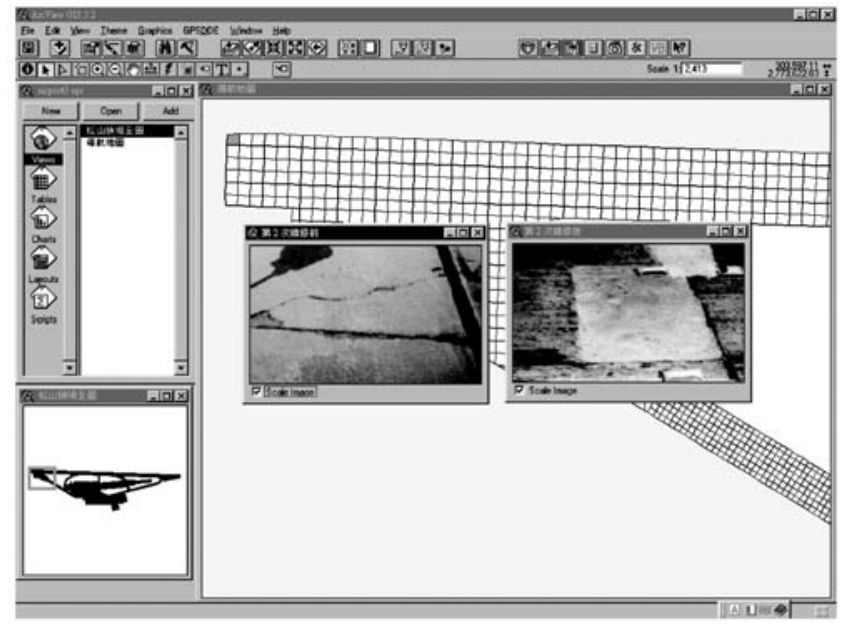

Fig. 8. Display the images of distressed slab before and after the repair.

ment using automatic image acquisition technology. Besides saving time and labor, this avoids the problem of overlooked data due to human fatigue or negligence, which might affect the correctness of survey results. The following problems should be noted, however:

(1) Survey speed: Due to the limitations of existing image recognition technology, the system currently employs only an industrial video recorder with a warning recording function. Because the locations of pavement damage are recorded manually as the observer watches the monitor, resolution and visual recognition speed limit survey speed. Future breakthroughs in image recognition technology may allow the development of an image recognition control method that could increase survey speed by automatically recording the locations of pavement damage.

(2) Measurement of damage dimensions: The system takes photographs in an oblique, downward direction in front of the vehicle. This increases the size of pavement photographs and facilitates the recording of damage locations by a manual operator. Since the resulting pictures are taken at a skewed angle, the current method of estimating the size of damage from the relative proportions of the image cannot accurately ascertain the size of the damage. This may affect the precision of subsequent interpretation. If mature automatic damage location control technology is developed in the future, it will be possible to employ a vertical photographic approach to improve the accuracy of damage size estimation.

(3) Although this system possesses automatic image acquisition and recording functions, personnel must constantly watch the monitor and press a button to record damage locations. Since it would be easy to miss data due to fatigue or negligence, it is suggested that future advances in image processing be used to develop control technology able to automatically record the locations of damage. This could further automate pavement survey work, enhancing efficiency.

\section{CONCLUSIONS}

(1) This study used a photographic system incorporating GPS and GIS functions mounted on a van. Image captioning and audio acquisition methods were employed to develop an automated airport pavement image collection system. Field trials have verified that this system is safer and more efficient than conventional manual walking surveys, and should be very useful in contemporary airport pavement maintenance work.

(2) This study incorporated GPS and GIS functions in an automated pavement image collection system. The recorded pavement damage images simultaneously display slab number and coordinates, which increases data resolution and improves on the current survey practice of recording mileage. The incorporation of GPS and GIS systems in automated pavement surveys is an inevitable future trend.

(3) The automatic image acquisition technology developed in this study is currently able to automatically acquire and save images of distressed pavement from the recorded videotape using computer software, and the image can store into every slab's database of pavement management system, it will make pavement maintenance management more efficient.

\section{REFERENCES}

1. "POS/LV Georgia DOT Test Results", Roadware Corporation, January, (1995).

2. Schwarz, K. P., and El-Sheimy, N. "Kinematic MultiSensor Systems for Close Range Digital Imaging", The $2^{\text {th }}$ National Conference on Global Positioning System, National Cheng Kung University, Taiwan, May, pp. 216 (1996).

3. Bursanescu, L., and Blais, F., "Automated Pavement Distress Data Collection and Analysis: a 3-D Approach", International Conference on 3-D Digital Imaging and Modeling, pp. 311-317 (1997).

4. Ali, M., Gennert, M. A., and Clarkson, T. G., "Analysis, Generation and Compression of Pavement Distress Images Using Fractals", The Applications of Fractals and Chaos, Springer-Verlag, Berlin, pp.147-169 (1993).

5. "Safe Roads", The Economist Newspaper Limited Lordon, June $23^{\text {rd }}$, (2001). 
6. Shahin, M. Y., "Pavement Management for Airports, Roads, and Parking Lots", Chapman \& Hall, New York, London, pp. 39-111 (1994).

7. "FHWA Crack System Tests at North Carolina-ARAN WiseCrax Results", Roadware Corporation, January, (1995).

8. "Functinal Description-ARAN Laser SDP", Roadware Corporation, (1995).

9. Swindall, B., Kobi, D., "High Speed Pavement Survey System", Roadware Corporation, (1995).

10. "Surveyor-Automated Facility Inventory System", Roadware Corporation, (1995)

11. "Multi-Laser Profilometer-High Speed Data Collection", Australian Road Research Board Ltd.

12. Mark Abkowitz, Stephen Walsh, Edwin Hdwin Hauser, and Larry Minor. "Adaption of Geographic Information Systems to Highway Management", Journal of Transportation Engineering, ASCE, Vol. 116, No. 3, pp. 310327 (1990).

13. Hofmann-Wellenhof, B., Lichtenegger, H., and Collins, J., "Global Positioning System Theory and Practice", Springer-Verlag Wien New York, pp. 201-209 (1992).

14. Chau Lee, Chen, C. F., and Wen-Shen Huang, "Establish of An Expert System for Repairing Airport Pavements", Report of Research Project on Behalf of the Ministry of Transportation and Communications, (2000)( in Chinese)
機場鋪面自動化影像菟集系統之研究

$$
\begin{aligned}
& \text { 李釗陳繼藩 } \\
& \text { 黄書猛許峻榕 }
\end{aligned}
$$

國立中央大學土木工程學系

$$
\text { 許書 王 }
$$

清雲技術學院土木工程學系

$$
\text { 摘 要 }
$$

機場鋪面的維護是機場鋪面管理系統中相當重 要的一環, 在現今繁忙的機場交通作業量下, 如何快 速有效的進行鋪面資料調查蒐集, 降低阻礙機場交通 正常作業的因子, 爲機場鋪面維修管理重要研究課 題。

本文運用汽車行進攝影方式, 並整合全球定位 系統(Global Positioning System, GPS)及地理資訊系 統(Geographic Information Systems, GIS), 利用影 像字幕器及音頻擷取法等, 發展一套機場鋪面自動化 影像蒐集系統。本系統目前已具有將鋪面影像與版塊 名稱、破損位置座標顯現於同一畫面及自動傾取破損 版塊畫面等功能, 可大幅增加鋪面調查速度, 所擷取 之畫面更可存入鋪面管理系統每一版塊的資料庫中, 對機場鋪面之維護工作應有相當的助益。

關鍵詞：機場鋪面、GIS、GPS。 